\title{
Investigation of Flexural Properties of Glass-Kevlar Hybrid Composite
}

\author{
Y. M. Kanitkar, A.P. Kulkarni, and K. S. Wangikar
}

\begin{abstract}
Composite materials are attracting huge attention due to their superior properties and being inert to most atmospheric effects. They have high strength to weight ratio and can be moulded into the required shape that can be used for various applications as replacement for metals. This paper consists of study of flexural behaviour of hybrid composite reinforced with woven glass fiber and Kevlar fiber in ply configuration. The three point bending test according to ASTM 790 was performed experimentally on this composite laminate. The fiber volume fraction to matrix volume fraction was taken $40 \%-60 \%$. The volume fraction of the individual fibers in the composite was varied to determine the effects on the flexural strength of the composite laminate. The laminates prepared were having dimension $80 \mathrm{~mm} X 13 \mathrm{~mm}$ X 3mm. After testing the $\mathrm{H} 4$ configuration had the highest flexural strength of 217.91 MPa also the $\mathrm{H} 2$ configuration had maximum flexural modulus. The result of the study can be used for the development of actual composites and simulation purpose.
\end{abstract}

Index Terms-Hybrid Composite, Kevlar Fiber, Glass Fiber, Flexural Strength.

\section{INTRODUCTION}

Composite materials are replacing the metals as an alternate material for various applications as they have high strength to weight ratio. The composites are made of fiber reinforcement bound by a matrix material [1]. The composites can be made from natural fiber and manmade fibers. The use of the natural fiber composites is limited to secondary applications and they possess less strength and they being biodegradable are not suitable for primary applications. This has led to the use of manmade materials which have high strength and are not susceptible to atmospheric effects [2]-[3].

Most famous manmade fibers used for making composites are Glass, Carbon, Kevlar, Asbestos, Ceramics etc. out of this Glass Carbon and Kevlar fibers are most prominently used for automobile body parts, sports goods, marine application, bullet-proofing, civil structures electric insulations, heat resistant clothes etc. [4]. The composites

Manuscript published July 31, 2016.

Y. M. Kanitkar is with the Mechanical Engineering Department Vishwakarma Institute of Information Technology, Pune-411048 India (email: yashmk92@gmial.com)

A. P. Kulkarni is with the Mechanical Engineering Department Vishwakarma Institute of Information Technology, Pune-411048 India. (email: atul.kulkarni@viit.ac.in).

K. S. Wangikar is with the Mechanical Engineering Department, Vishwakarma Institute of Information Technology, Pune-411048 India (email: kiran.wangikar@viit.ac.in). made out of any one fiber is called pure composites which gives specific characteristic like composite made from Carbon or Kevlar fibers have superior strengths but are very costly whereas the composite made from Glass fibers are cheap but their strengths is less. So to achieve the balance between the strengths and cost of composite, two or more fibers are being mixed to make composite this type of composites are called hybrid composites. The hybrid composites have the advantage of low cost and strengths greater than the weaker material but less than the stronger material. Essentially the hybrid composite can be defined as a composite consisting two or more different kinds of material as it reinforcement [5]-[7].

Many experimental works are being carried out on the hybrid composite for more than 30 years to study the effects of hybridization on the properties of the composite [8]-[16]. Aramide fibers have drawn lot of focus as it is heat resistant and high strength fibers, the fibers have tensile strength of $2.8 \mathrm{GPa}$ and modulus of elasticity of $109 \mathrm{GPa}$. Functional aramides have found their way into various applications as industrial materials, bulletproof and protective shields, marine fishery parts and civil structures [17]-[20].

The fiber volume fraction plays and important role in determining the strength of the composite prepared. Rejab et al. investigated the effects of fiber volume fraction on GFRP Plate. The volume fractions used for the experimentation were $20-80 \%, 30-70 \%$, 40-60\% Fiber to Matrix volume ratio respectively. The optimum tensile and compressive strength was observed in the case for $40 \%-60 \%$ fiber to matrix volume ratios. It was seen that as the fiber volume increased in the composite the strengths also increased but after certain limit as fiber volume fraction increases the amount of matrix material decreases and it starts weakening interfacial bonding strength between fibers and binder material [21].

Dong et al. investigated the effect of different volume fractions of S-2 glass and T700S carbon fiber on the flexure strength of the composite. The optimum hybrid effect was achieved when the hybrid ratio was 0.125 ([0G/07C]) when both Vfc and Vfg were $50 \%$ and the increases in strength was $43.46 \%$ and $85.57 \%$ when compared with those of the full carbon and glass configurations respectively. The optimisation shows that the maximum hybrid effect was $56.1 \%$ when $\mathrm{Vfc}=47.48 \%$ and $\mathrm{Vfg}=63.29 \%$ [22].

Along with the fiber volume fraction the fiber orientation also play an important role for change in mechanical properties. Various experiments were carried out using different fiber orientation like $0^{\circ}, 90^{\circ},+45^{\circ},-45^{\circ}$ fiber orientation in the composite laminate and the $90^{\circ}$ and $+45^{\circ}$ 
orientation gave maximum tensile strengths out of all the combinations [23]-[25].

Many researchers have tested the mechanical properties of composite having different layering sequences and results obtained proved that layering sequence affected the mechanical properties of the composites. For instance Sarasini et al. prepared the composite having sandwich-like stacking sequence and the other one with an intercalated fabrics lay-up for carbon laminates and performed low velocity impact tesing and observed hybrid laminates with

Sandwich configuration failed by interface failures located in the basalt skins of the compression side which prevented hindering crack propagation in the carbon core. Another researcher Zhang et al. used Glass-Carbon hybrid composite having different stacking sequence to determine the mechanical properties like tensile, compression and three point bending and it was found that the hybrid containing $50 \%$ carbon fibers showed improvement in the flexure properties when carbon fibers are kept at exterior region, and alternating carbon/glass layup gave good compressive strength and tensile strength was not affected by the stacking sequence. [26]-[29].

Flexural strength is usually measured using three point bending test. For this test when loading is done the upper side of the specimen will experience compression and the lower side will experience tension and at mid plane the specimen will experience shear stress. Using this principle when Prusty et al. [30] replaced four glass plies out of seven ply composite laminate by carbon it was found that by the carbon at tensile side showed improvement in strengths and modulus but the laminate was more prone to catastrophic failure whereas at the compressive side the carbon epoxy showed progressive failure also the laminate had $93 \%$ modulus and $96 \%$ strength as that of laminate made entirely of carbon epoxy.

Another researcher Dongs [31] choose two types of glass S-2 and E, and two Carbon fiber T700S and P-100 and determined the flexural strength using three different models namely Lo-Chim, Budiansky and the shear model. The flexural strength obtained by first two models was nearly similar but the flexural strength obtained by shear model was $20-30 \%$ lower. And Sudarisman and Davies [32] noted that when E-glass fibers were replaced by $33 \%$ of S-2 glass fibers the flexural strength increased by $23 \%$, and it did not have any significant effect on flexural modulus. Kalnin [33] found that the flexural strength decreases rapidly as all-glass reinforcement is progressively replaced by graphite fibre. Slight positive deviations were shown from the theoretical maximum strain failure criteria.

\section{EXPERIMENTAL DETAILS}

\section{A. Marerials}

The laminates prepare for mechanical testing consist of Kevlar fiber $200 \mathrm{GSM}$ and Glass fiber 200GSM having $0^{\circ}$ and $90^{\circ}$ orientation. The Kevlar fibers have density of 1.40 $\mathrm{g} / \mathrm{cc}$ which was taken from the manufacturer's catalogue as shown in Table I. The glass fiber in form of woven mat was used and the density of Glass fiber mat is $1.90 \mathrm{~g} / \mathrm{cc}$ shown in Table II. The liquid type XR-125 epoxy resin having density 1 is used for preparing the laminates. The details of which are given in Table III. Fig. 1, Fig. 2 and Fig. 3 shows the Glass fiber, Kevlar Fiber and Epoxy Resin and Hardener used for manufacturing the composite

\begin{tabular}{ccc}
\multicolumn{3}{c}{ TABLE I: PROPERTY OF KEVLAR FiBERS } \\
\hline Property & Unit & Value \\
\hline Width & $\mathrm{cm}$ & 150 \\
Weight & $\mathrm{g} / \mathrm{m} 2$ & 192 \\
EPI (Warp) & ea & 21 \\
EPI (Weft) & ea & 20.8 \\
Breaking Strength (Warp) & $\mathrm{N} / 5 \mathrm{~cm}$ & 8647 \\
Breaking Strength (Weft) & $\mathrm{N} / 5 \mathrm{~cm}$ & 7887 \\
Thickness & $\mathrm{mm}$ & 0.3 \\
\hline
\end{tabular}

\begin{tabular}{|c|c|c|}
\hline \multicolumn{3}{|c|}{ TABLE II: PROPERTY OF GLASS FIBERS } \\
\hline Property & Units & Value \\
\hline Single Filament Tensile & $\mathrm{MPa}$ & $3100-3800$ \\
\hline \multicolumn{3}{|l|}{ Strength } \\
\hline Single Filament Tensile & Kpsi & $450-550$ \\
\hline \multicolumn{3}{|l|}{ Strength } \\
\hline Young's Modulus of & $\mathrm{GPa}$ & $80-81$ \\
\hline \multicolumn{3}{|l|}{ Elasticity } \\
\hline Young's Modulus of & Mpsi & $11.6-11.8$ \\
\hline \multicolumn{3}{|l|}{ Elasticity } \\
\hline Fiber Density & $\mathrm{g} / \mathrm{cc}$ & 2.62 \\
\hline \multicolumn{3}{|c|}{ TABLE III: PROPERTY OF EPOXY RESIN } \\
\hline Property & Unit & Value \\
\hline Tensile Strength & $\mathrm{MPa}$ & $50-60$ \\
\hline Flexural Strength & $\mathrm{MPa}$ & $120-130$ \\
\hline Elastic Modulus in Flexural & $\mathrm{GPa}$ & $3-3.5$ \\
\hline
\end{tabular}

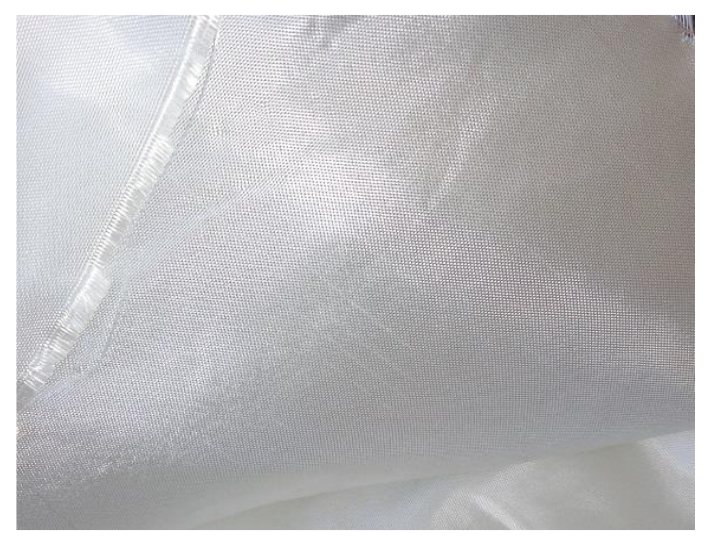

Fig. 1. Glass Fiber Cloth 

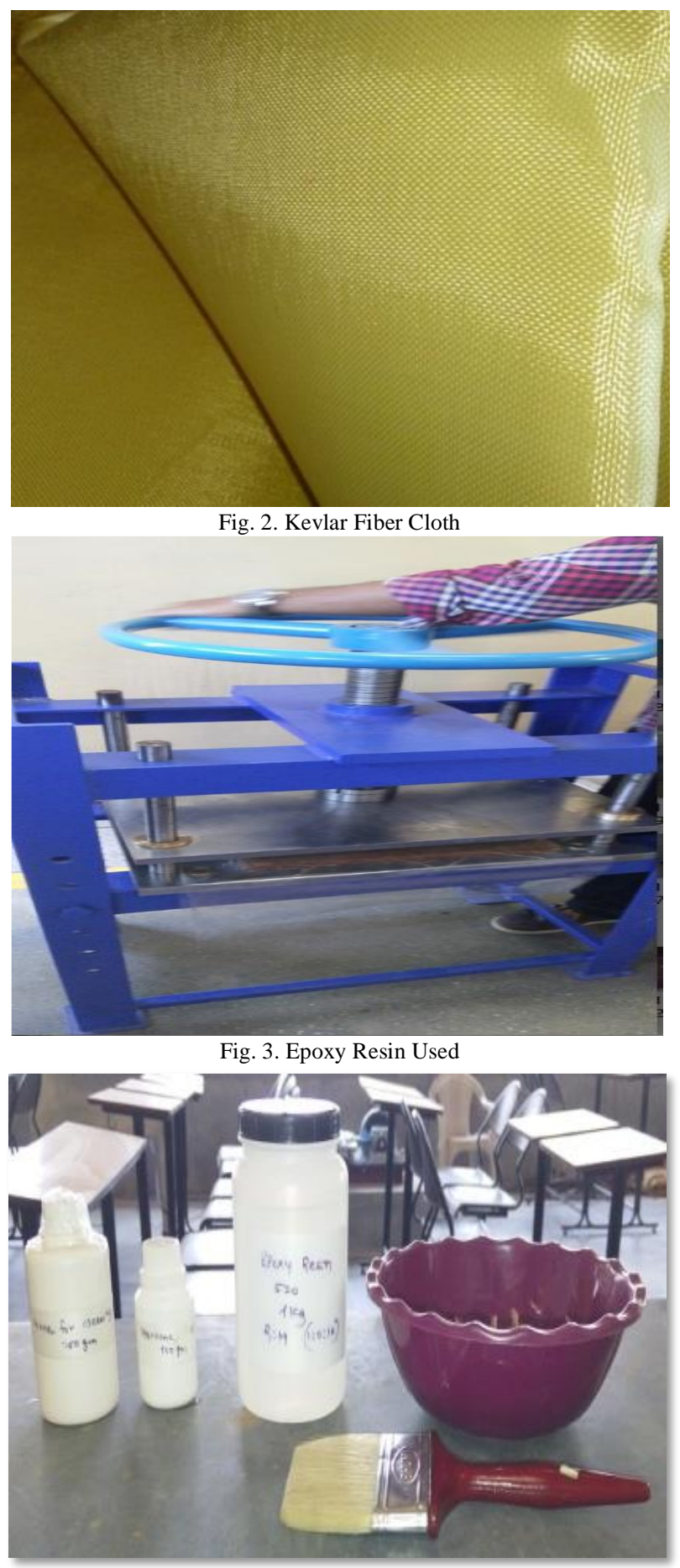

Fig. 4. Preparation of Laminate

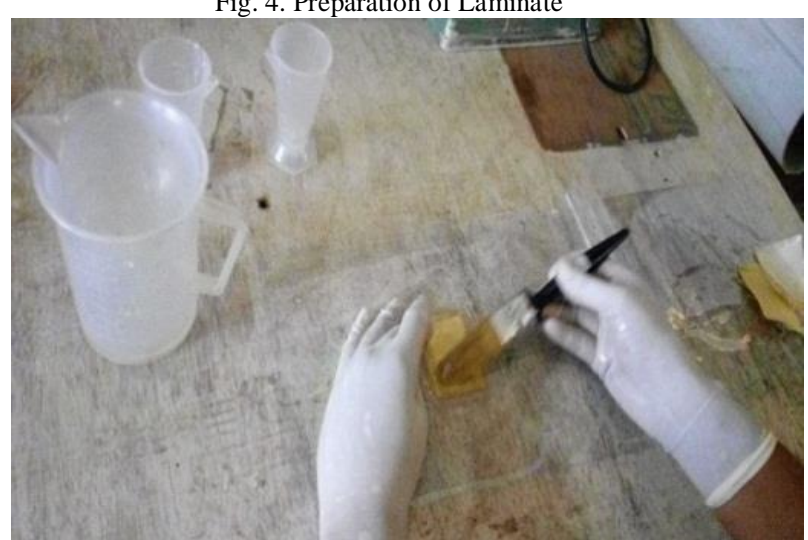

Fig. 5. Application of Pressure using Compression Molding Machine

\section{B. Composite Laminate Preparation and sample configuration}

The Glass fiber and the Kevlar fiber laminates having epoxy resin as the matrix material were prepared using the hand-lay-up method. The Glass and Kevlar fiber mats were hand laid-up using epoxy matrix as a binder which contained the mixture of epoxy resin and hardener in the ratio of 10:1 as shown in Fig. 4. Total six laminates were prepared with the configuration as given in the Table IV. The laminates were made using the compression molding machine and covering plastic was used on the outer surface of the laminate so the epoxy matrix would not stick to the metal plates of the compression molding machine and it also provided smooth and even outer surface it as shown in Fig. 5 and Fig. 6 shows the manufactured composite laminate.

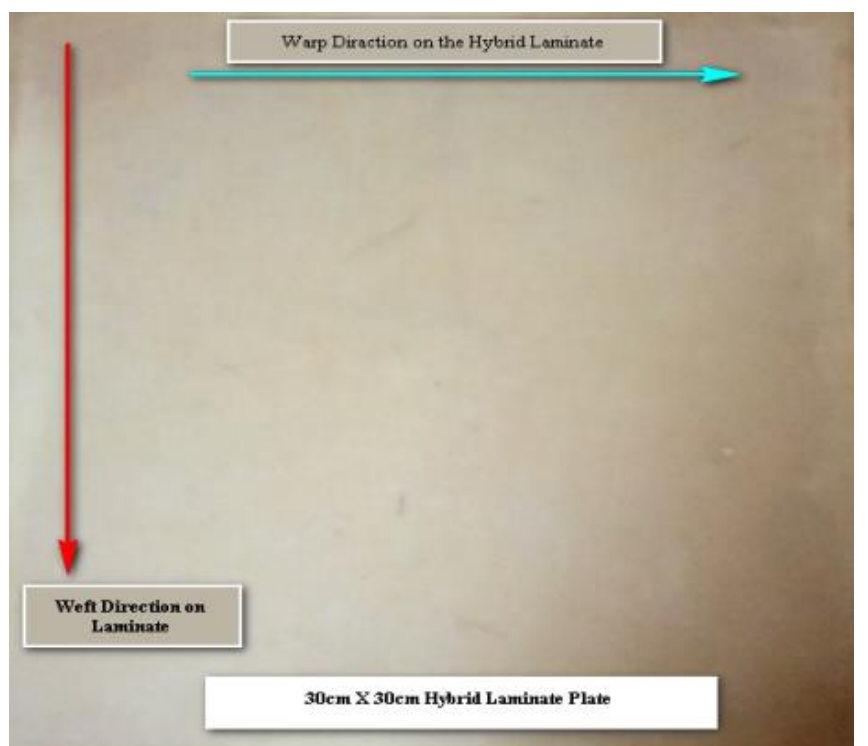

Fig. 6. Manufactured laminate of size $30 \mathrm{cmX} 30 \mathrm{cmX} 0.3 \mathrm{~cm}$

TABLE IV: Fiber VOLUME FRACTION AND FIBER SEQUENCE

\begin{tabular}{|c|c|c|c|c|c|}
\hline $\begin{array}{l}\text { Lamin } \\
\text { ate } \\
\text { Numb } \\
\text { er }\end{array}$ & $\begin{array}{l}\text { Volume } \\
\text { Fraction } \\
\text { of Fiber to } \\
\text { Matrix }\end{array}$ & $\begin{array}{l}\text { Num } \\
\text { ber } \\
\text { of } \\
\text { Glas } \\
\text { s } \\
\text { Fiber } \\
\text { Laye } \\
\text { rs }\end{array}$ & $\begin{array}{l}\text { Numb } \\
\text { er of } \\
\text { Kevlar } \\
\text { Fiber } \\
\text { Layers }\end{array}$ & $\begin{array}{ll}\text { Volume } & \\
\text { Fraction of } \\
\text { Glass to } \\
\text { Kevlar fiber } \\
\text { in } 40 \% \text { fiber } \\
\text { volume }\end{array}$ & Sequence \\
\hline H1 & $40 \%-60 \%$ & 5 & 4 & $21 \%-19 \%$ & $\begin{array}{l}\text { G-K-G-K-G- } \\
\text { K-G-K-G }\end{array}$ \\
\hline $\mathrm{H} 2$ & $40 \%-60 \%$ & 6 & 3 & $25 \%-15 \%$ & $\begin{array}{l}\text { G-K-G-G-K- } \\
\text { G-G-K-G }\end{array}$ \\
\hline $\mathrm{H} 3$ & $40 \%-60 \%$ & 7 & 2 & $30 \%-10 \%$ & $\begin{array}{l}\text { G-G-G-K-G- } \\
\text { K-G-G-G }\end{array}$ \\
\hline $\mathrm{H} 4$ & $40 \%-60 \%$ & 4 & 5 & $16 \%-24 \%$ & $\begin{array}{l}\text { G-K-G-K-K- } \\
\text { K-G-K-G }\end{array}$ \\
\hline H5 & $40 \%-60 \%$ & 3 & 6 & $12 \%-28 \%$ & $\begin{array}{l}\text { G-K-K-K-G- } \\
\text { K-K-K-G }\end{array}$ \\
\hline H6 & $40 \%-60 \%$ & 2 & 7 & $7 \%-33 \%$ & $\begin{array}{l}\text { G-K-K-K-K- } \\
\text { K-K-K-G }\end{array}$ \\
\hline
\end{tabular}

\section{Fiber Volume Fraction Calculation}

It is defined as the amount of fiber contained in the composite. Higher the volume fraction of fibers in the composite results in the enhanced mechanical properties but there is certain limitation that is after certain limit as fiber volume fraction increases the amount of matrix material 
decreases and it starts weakening interfacial bonding strength between fibers and binder material. So to achieve best mechanical properties the fiber volume fraction is kept $40 \%$ in the laminate and the volume fraction is calculated using the following formula: [22]

$$
V_{f}=\frac{W f / \rho_{f}}{W_{m} / \rho_{m}{ }^{+}{ }^{W 1} / \rho_{f 1}{ }^{{ }}{ }^{W 2} / \rho_{f 2}} * 100
$$

Where

$$
V_{f}=\text { Fiber Volume Fraction }
$$

$W f=$ Weight fraction of Fiber

$\rho_{f}=$ Density of Fiber

$W_{m}=$ Weight of Marix

$\rho_{m}=$ Density of Matrix

$W_{f 1}=$ Weight fraction of 1 st Fiber

$\rho_{f 1}=$ Density of 1 st Fiber

$W_{f 2}=$ Weight fraction of 2 nd Fiber

$\rho_{f 2}=$ Density of 2 nd Fiber

Also from the literature it is clear that the Glass fibers is better resistant to the atmospheric effects then the Kevlar fiber and it being the material having very high strength is the most suitable material for making the core portion the laminate. The arrangement of the Glass fibers and Kevlar fibers along with their respective volume fraction inside the composite laminate and the total volume fraction of the fiber to matrix is given in the Table IV.

\section{Flexural Test}

Flexural test or three point bending test was performed to determine the stress-strain relationship and the flexural modulus of the composite laminate having different combination of Glass and Kevlar fibers was carried out according to ASTM D790. The specimen were cut using water get machining and the dimensions of length by width by thickness were $80 \mathrm{~mm} X 13 \mathrm{~mm} X 3 \mathrm{~mm}$ respectively. The specimen was tested on Universal Testing Machine with model no- STS 248 , having speed $5 \mathrm{~mm} / \mathrm{min}$ and with the accuracy of $\pm 1 \%$. The flexural test specimen and testing of specimen is shown in the Fig 5.

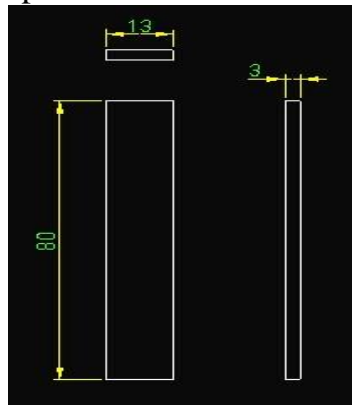

Fig. 5. Flexural Test Specimen Dimensions and Flexural Testing of Specimen

\section{RESULTS AND DisCUSSIONS}

The results obtained after performing the experiments on the specimen are summarized in the Table V. Total five tests were carried out for one configuration and the average of all the five test result are summarized in the table.

TABLE V: FLEXURAL STRENGTH AND FLEXURAL MODULUS

$\begin{array}{rrr}\text { Specimen } & \text { Flexural } & \text { Flexural } \\ \text { onfiguration } & \text { Strength(MPa) } & \text { Modulus(Gpa) }\end{array}$

\begin{tabular}{lcc}
\hline H1 & 196.43 & 11.016 \\
H2 & 174.16 & 15.810 \\
H4 & 90.23 & 4.483 \\
H5 & 217.91 & 12.821 \\
H6 & 199.99 & 13.883 \\
& 199.99 & 11.653 \\
\hline
\end{tabular}

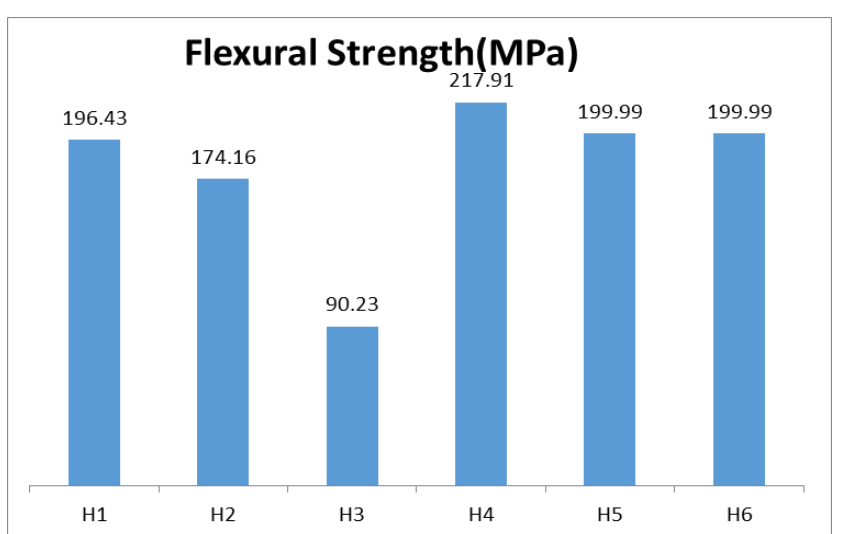

Fig. 6. Application of Pressure using Compression Molding Machine

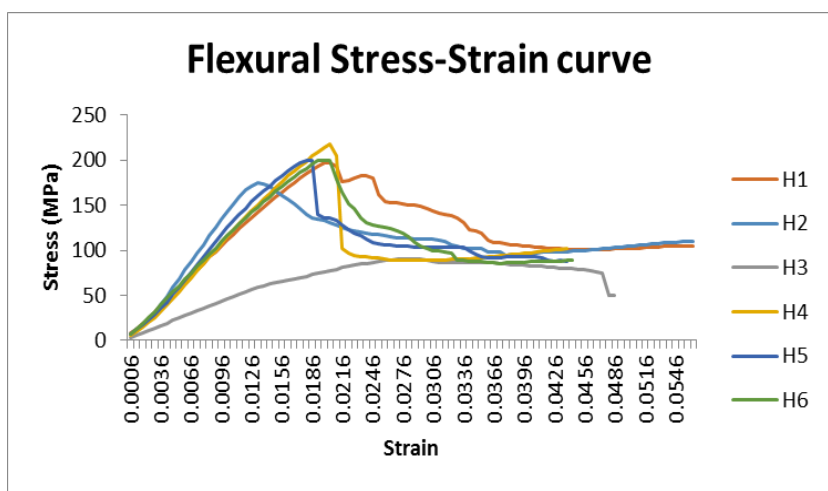

Fig. 7. Flexural Stress-Strain Curve

The Table V, Fig. 6 and Fig. 7 shows the values of flexural strengths and also the stress-strain relationship is shown in which gives the flexural modulus. The configuration $\mathrm{H} 4$ has the maximum flexural strength of 217.91 MPa, closely followed by $\mathrm{H} 5, \mathrm{H} 6$ and $\mathrm{H} 1$ configuration. It can be seen that the introduction of glass fiber with volume fraction $21 \%$ and $16 \%$ has positive hybridisation effect on the hybrid composite but as the volume of glass fiber increases from $21 \%$ to $30 \%$ the flexural strength decreases significantly indicating if the high volume of glass fiber leads to negative hybridisation effect on the composite. This same phenomenon happen in case if the Kevlar fiber volume is kept more than the Glass 
fiber volume but the drop in strength is not so significant as compare when Glass fiber is dominating the composite. This indicates that the volume fraction of Glass fiber to Kevlar fiber must be kept at $16 \%-24 \%$ respectively.

\section{REFERENCES}

[1] Leman Z, Sapuan SM, Azwan M, Ahmad MMHM, Maleque M, "The Effect of Environmental Treatments on Fiber Surface Properties and Tensile Strength of Sugar Palm Fiber-Reinforced Epoxy Composites," Polymer Plastic Technology Engineering 2008; 47: 606-12.

[2] Anwar UMK, Paridah MT, Hamdan H, Sapuan SM, Bakar ES., "Effect of curing time on physical and mechanical properties of phenolic-treated bamboo strips." Ind Crops Prod 2009;29:2149.

[3] Sapuan SM, Harimi M, Maleque MA. "Mechanical Properties of Epoxy / Coconut Shell Filler Particle Composites," Arab J Sci Eng 2003;28:171-81.

[4] Rashdi AAA, Sapuan SM, Ahmad MMHM, Khalina A "Combined effects of water absorption due to water immersion, soil buried and natural weather on mechanical properties of kenaf fibre unsaturated polyester composites (KFUPC)" International Journal of Mechanical Materials and Engineering 2010;5:11-7.

[5] Jawaid M, Abdul Khalil HPS, Abu Bakar "Woven hybrid composites: Tensile and flexural properties of oil palm-woven jute fibres based epoxy composites" Material Science and Engineering A 2011;528:5190-5.

[6] Wambua P, Vangrimde B, Lomov S, Verpoest I. "The response of natural fibre composites to ballistic impact by fragment simulating projectiles" Composite Structure 2007; 77: 232-40.

[7] Mishra S, Mohanty AK, Drzal L., Misra M, Parija S, Nayak S., "Studies on mechanical performance of bio-fibre/glass reinforced polyester hybrid composites" Composite Science and Technology 2003;63:1377-85.

[8] Fu Shao-Yun et al. Hybrid effects on tensile properties of hybrid short-glass-fiber and short-carbon-fiber reinforced polypropylene composites" Journal of Material Sciences 2001; 36(5): 1243-51.

[9] Fu Shao-Yun, Guanshui Xu, Yiu-Wing Mai "On the elastic modulus of hybrid particle/short-fiber/polymer composites" Composite Part B: Engineering 2002;33(4):291-9.

[10] Sonparote PW, Lakkad SC. "Mechanical properties of carbon/glass fibre reinforced hybrids," Fibre Science and Technology 1982; 16(4): 309-12.

[11] Venkateshwaran N, Elayaperumal A, Sathiya GK. "Prediction of tensile properties of hybrid-natural fiber composites," Compos Part B: Engineering 2012; 43(2): 793-6.

[12] Atiqah A et al. "Development of Kenaf-glass reinforced unsaturated polyester hybrid composite for structural applications" Composite Part B: Engineering 2013.

[13] Jarukumjorn Kasama, Suppakarn Nitinat. "Effect of glass fiber hybridization on properties of sisal fiber-polypropylene composites," Compos Part B: Engineering 2009; 40(7): 623-7.

[14] Jawaid M et al. "Effect of jute fibre loading on tensile and dynamic mechanical properties of oil palm epoxy composites," Compos Part B: Engineering 2013;45(1):619-24.

[15] Ramesh M, Palanikumar K, Hemachandra Reddy K. "Mechanical property evaluation of sisal-jute-glass fiber reinforced polyester composites," Compos Part B: Engineering 2012.

[16] Boopalan M, Niranjanaa M, Umapathy MJ. "Study on the mechanical properties and thermal properties of jute and banana fiber reinforced epoxy hybrid composites," Compos Part B: Engineering 2013.

[17] Horrocks AR. "Flame retardant challenges for textiles and fibres: new chemistry versus innovatory solutions," Polymer Degradation and Stability 2011; 96(3): 377e92.

[18] Horrocks AR, Kandola BK, Davies PJ, Zhang S, Padbury SA. "Developments in flame retardant textiles e a review," Polymer Degradation and Stability 2005;88(1):3e12.
[19] Flambard X, Bourbigot S, Ferreira M, Vermeulen B, Poutch F. "Wool/para-aramid fibres blended in spun yarns as heat and fire resistant fabrics," Polymer Degradation Stability 2002; 77(2): $279 \mathrm{e} 84$.

[20] Horrocks AR. "Textile flammability research since 1980 e personal challenges and partial solutions," Polymer Degradation Stability 2013; 98(12): 2813e24.

[21] M.R.M.Rejab, C.W.Theng, M.M.Rahman, M.M.Noor and A.N.M.Rose "An Investigation into the Effects of Fibre Volume Fraction on GFRP Plate" Proceedings of MUCET2008.

[22] Chensong Dong, Ian J. Davies "Flexural Strength of Bidirectional Hybrid Epoxy Composites Reinforced by E Glass and T700S Carbon Fibres" Composites: Part B

[23] Yiming $\mathrm{Fu}, \mathrm{Pu}$ Zhang, Fan Yang "Interlaminar stress distribution of composite laminated plates with functionally graded fiber volume fraction," Materials and Design 31 (2010) 2904-2915

[24] L.H. Qi, Y.Q.Ma, J.M.Zhou, X.H.Hou, H.J.Li "Effect of fiber orientation on mechanical properties of $2 \mathrm{D}-\mathrm{Cf} / \mathrm{Al}$ composites by liquid-solid extrusion following Vacuum infiltration technique," Materials Science \& Engineering A625(2015)343349

[25] Wei Xiong, Bamber Blackman, John P. Dear, Xichang Wang "The effect of composite orientation on the mechanical properties of hybrid joints strengthened by surfi-sculpt," Composite Structures 134 (2015) 587-592

[26] R.Yahaya, S.M. Sapuan, M.Jawaid, Z. Leman and E.S. Zainudin "Effect of fibre orientations on the mechanical properties of kenaf-aramid hybrid composites for spall-liner application," Defence Technology

[27] F. Sarasini, J. Tirillo, L. Ferrante, M. Valente, T. Valente, L. Lampani, P. Gaudenzi, S. Cioffi, S. Iannace, L. Sorrentino "Drop-weight impact behaviour of woven hybrid basaltcarbon/epoxy composites," Composites: Part B 59 (2014) 204220

[28] Jin Zhang, Khunlavit Chaisombat, Shuai He, Chun H. Wang "Hybrid composite laminates reinforced with glass/carbon woven fabrics for lightweight load bearing structures" Materials and Design 36 (2012) 75-80/.

[29] Smolin AY, Shilko EV, Astafurov SV, Konovalenko IS, Buyakova SP, Psakhie SG. "Modelling mechanical behaviours of composites with various ratios of matrix-inclusion properties using movable cellular automaton method," Defence Technology 2015;11:18-34.

[30] Rajesh Kumar Prusty , Dinesh Kumar Rathore, Bhanu Pratap Singh, Sarat Chandra Mohanty, Kishore Kumar Mahato, Bankim Chandra Ray "Experimental optimization of flexural behaviour through inter-ply fibre hybridization in FRP composite," Construction and Building Materials 118 (2016) 327-336

[31] Chensong Dong "Uncertainties in flexural strength of carbon/glass fibre reinforced hybrid epoxy composites," Composites Part B (2016), doi: 10.1016 /j. composites b 2016.05.035.

[32] Sudarisman, Davies IJ, "The effects of processing parameters on the flexural properties of unidirectional carbon fibre-reinforced polymer (CFRP) composites," Mater Sci Eng:A 2008;498:65-8.

[33] Kalnin IL. "Evaluation of unidirectional glass-graphite fibre/epoxy resin composites," Composite materials: testing and design. Baltimore, MD, USA: American Society for Testing and Materials; 1972. p. 551-63

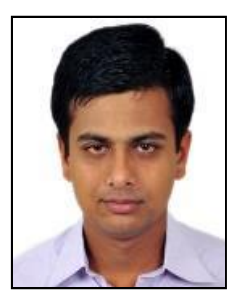

project submission.
Yash M. Kanitkar was born in bardoli taluka, of Surat district in India on $7^{\text {th }}$ August 1992. He has completed his Bachelors of Engineering in Mechanincal Engineering from GTU, Ahmedabad, Gujarat, India and is currently pursuing "Masters of Design Engineering" from VIIT, Pune India.

The research work is undertaken for completing his Final year Thesis work. This research is part of the Thesis work being carried out for the final year 